\title{
The Effectiveness of Collaborative Teaching Method in Teaching Calculus I
}

\author{
Muhammad Yassar Yusri, Shamsatun Nahar Ahmad, Mohd Hanafi Azman Ong, Nosiah Khalil \\ Faculty of Computer and Mathematical Sciences, \\ Universiti Teknologi MARA, Johor, Malaysia \\ muham449@uitm.edu.my, shams551@uitm.edu.my, napieong@yahoo.com,nosia272@gmail.com \\ Tel: $+6013-7944826$
}

\begin{abstract}
The collaborative teaching method is a method that requires students working together in groups to solve problems to perform better in their studies. This paper aims to determine the method's effectiveness in teaching Calculus I in UiTMCJ. Some students were chosen to participate in this study. They were taught Calculus I using this method and were assessed by using pre-assessment and post-assessment questions. The scores were analyzed using the paired T-test method. The results suggest that this method is effective to be used to teach Calculus I in UiTMCJ.
\end{abstract}

Keywords: Collaborative teaching; Calculus I; concept, paired T-test

eISSN: 2398-4287 @ 2020. The Authors. Published for AMER ABRA cE-Bs by e-International Publishing House, Ltd., UK. This is an open access article under the CC BYNC-ND license (http://creativecommons.org/licenses/by-nc-nd/4.0/). Peer-review under responsibility of AMER (Association of Malaysian Environment-Behaviour Researchers), ABRA (Association of Behavioural Researchers on Asians) and cE-Bs (Centre for Environment-Behaviour Studies), Faculty of Architecture, Planning \& Surveying, Universiti Teknologi MARA, Malaysia. DOI: https://doi.org/10.21834/ebpj.v5iSI1.2319

\subsection{Introduction}

Calculus 1 is one of the main courses for diploma students of Mathematical Sciences and Computer Sciences in Universiti Teknologi MARA, Cawangan Johor, Malaysia. The failure rate for Calculus 1 is a severe problem for Computer Science students because almost every semester more than 25 percent of the students failed this course, hence failing to graduate on time since the course has to be retaken in the following semester. Therefore, to reduce the percentage of failure, the researchers decided to implement a different teaching method in the class. This method is the collaborative teaching method. The collaborative teaching method is a teaching method that has a lot of benefits in improving the performance of students. Davidson and Major (2014) defined collaborative learning as a method where the learners and the teacher work together in an attempt to produce knowledge.

The purpose of this research is to determine the effectiveness of the collaborative teaching method in teaching Calculus I in Universiti Teknologi MARA Cawangan Johor. In this research, the collaborative teaching method was implemented to teach Calculus I lessons for a group of Diploma-level students in UiTMCJ.

\subsection{Literature Review}

The collaborative teaching method is not new, but it remains valid as one of the effective teaching methods in the education field. This method is done by first letting the students acquire new information via lecture, reading or from the media. The students are then given the freedom to explore the latest information by themselves. Students will discuss the latest information with each other and come out with their understanding of the topic. Lecturers will be available to help or correct them if they have misunderstood a concept. Consequently, for a learning exercise to be defined as collaborative learning, Laal, Khattami-Kermanshahi, and Laal (2014) described that there must be elements of positive interdependence, an interaction between students, individual responsibility among participants, and social skills and group processing in the exercise. Collaborative learning aims to encourage students to take considerable responsibility to work together and help them to create new knowledge together (Davidson and Major, 2014).

eISSN: 2398-4287 ( 2020. The Authors. Published for AMER ABRA cE-Bs by e-International Publishing House, Ltd., UK. This is an open access article under the CC BYNC-ND license (http://creativecommons.org/licenses/by-nc-nd/4.0/). Peer-review under responsibility of AMER (Association of Malaysian Environment-Behaviour Researchers), ABRA (Association of Behavioural Researchers on Asians) and cE-Bs (Centre for Environment-Behaviour Studies), Faculty of Architecture, Planning \& Surveying, Universiti Teknologi MARA, Malaysia.

DOI: https://doi.org/10.21834/ebpj.v5iSI1.2319 
The collaborative teaching method has a lot of benefits for students. One of the main benefits is that this method encourages students to work in a team. Also, Diaz, Brown, and Salmons (2010) agree that collaborative learning helps students to learn how to work together as it will become a valuable skill to have in a workplace. By working together, they can also improve their confidence, motivation, soft skills, and moral values (Hasanpour-Dehkordi and Solati, 2016). One further benefit of collaborative learning is that it helps students to develop critical thinking and problem-solving skills, as suggested by several types of research (Hagman, Johnson, and Fosdick, 2017; Laal and Ghodsi, 2012). These skills are also precious for students to have to be successful in their future careers.

Ahmad et al. (2017) have worked on the students' behaviour, whereby the results showed that self-effort was the related factor for students' performance in Calculus 1. This paper continues the research of Ahmad et al. (2017) by focusing on the teaching method as another critical aspect of teaching and learning Calculus 1, besides the behaviour of students. Mann and Enderson (2017) claimed that students preferred the procedural teaching approach compared to the conceptual teaching approach. Usually, students prefer to directly get the formula to solve the problem rather than understanding the concept behind it. This situation implies that students have difficulties in learning concept-related knowledge and would instead memorize the formula to solve a problem. However, more Mathematical Science students are conceptually good according to research by Engelbrecht, Harding, and Potgieter (2005).

\subsection{Methodology}

In this research, a group of students consisting of 53 students who took the course for the first time and students who repeat the subject was chosen randomly among all the students taking Calculus 1 in semester 2 2016/2017 as samples as shown in Table 1.

\begin{tabular}{|c|c|} 
Table 1: Samples for Experiment \\
\begin{tabular}{|c|c|}
\hline Students & Sample size \\
\hline First time taking Calculus 1 & $39 / 110$ \\
\hline Repeat Calculus 1 & $14 / 41$ \\
\hline Total sample & $53 / 151$ \\
\hline
\end{tabular}
\end{tabular}

The students were then provided a set of 10 calculus questions for them to answer. The results of this set were then taken as preassessment scores and not returned to the students; therefore, the correct answer would not be known to them. Then, students attended 14 weeks of Calculus I lessons taught by using the collaborative teaching method. The lecturer first taught the class about the topic of the day. A principle of collaborative teaching in the classroom was formed, and the students were strict to follow it. The students were then divided into groups of four and were allowed to discuss the topic among them, give comments and share the answers to other group members. At the same time, the lecturer walked around the class to make corrections or clear misconceptions, if necessary. After that, the students were asked to solve some questions on the whiteboard in front of the class. The solution was then checked by the lecturer and the other students. After 14 weeks of class sessions, students were then given a set of the same questions as a postassessment test. The post-assessment scores were compared with the pre-assessment scores and were analyzed by using the paired t-test method since the methodology allows the researchers to test the paired data at the two points of assessments (Field, 2010). The test statistics for this analysis method is:

$$
t=\frac{\bar{y}_{\text {PreTest }}-\bar{y}_{\text {PostTest }}}{S E\left(\bar{y}_{\text {PreTest }}-\bar{y}_{\text {PostTest }}\right)}
$$

Where $\bar{y}_{\text {PreTest }}$ is the average marks for the Pre-Test assessment, $\bar{y}_{\text {PostTest }}$ is the average marks for the Post-Test evaluation, and $S E\left(\bar{y}_{\text {PreTest }}-\bar{y}_{\text {Post Test }}\right)$ is the standard error of the Difference between Pre-Test assessment and Post-Test assessment.

On the other hand, Field (2009) also suggests performing the effect size measurement if the findings of the paired t-test are significantly different. It is because the researchers can access the impact of the experiment method that was used in this research. The formula for estimating the effect sizes is:

$$
\text { Effect Size }=\frac{(\text { Paired } t-\text { test statistics })^{2}}{(\text { Paired } t \text { - test statistics })^{2}+d f}
$$

Where 'Paired t-test statistics' is the test statistic that has been estimated from Equation 1 and $d f$ is the degree of freedom for the test statistic that has also been calculated from Equation 1.

The set of questions was initially divided into three categories: 1) Basic knowledge of mathematical concepts, 2) Mathematics preknowledge from previous education levels, and 3) calculus knowledge (differentiation and integration). These three categories were chosen because they are critical problems for Computer Science students that contribute to the high failure rate in UiTMCJ. This problem can also be seen in students from other fields, such as engineering students. Engelbrecht, Bergsten, and Kagesten (2012) found that more engineering students from Sweden are weak in solving conceptual questions compared to procedural questions. Thus, conceptual questions are seen to be one of the problems and must be developed in the first category. One question that consists of 16 items was designed for fundamental concepts in calculus. 
The second category is Mathematics pre-knowledge from previous education levels. The students' knowledge from secondary schools may have already shaped their perception or understanding of some Calculus topics (Petocz et al., 2007). For instance, science, technology, engineering, and mathematics students who possess no prior knowledge of calculus are more likely to have fewer opportunities to learn as opposed to students who have learned calculus during high school in Hagman et al. (2017). Therefore, preknowledge is very important before learning calculus. Hence, in this paper, six questions were developed for pre-knowledge that consists of the evaluation of functions, solving equations and inequalities, composite functions, and solving trigonometry equations.

The third category is the students' understanding of calculus knowledge. This research aims to test the effectiveness of the collaborative teaching method by using it to teach Diploma-level calculus, particularly limit, differentiation, and integration. The students' understanding of the fundamental calculus concept is crucial for them to understand the more complex terms of calculus. For example, in Burns (2014), students who understand a quadratic function's vertex do shape the understanding of the derivative. In Serhan (2015), Calculus II students who have a poor understanding of the basic concepts of integration found it harder to solve more complex problems involving integration. Therefore, three questions were developed that consist of six items for differentiation, one item for finding the equation of a tangent line to the graph and three items for integration.

Figure 1 shows the graph analysis of the paired data between the pre-assessment and post-assessment of the targeted variables. The graph indicates that, generally, there is an increase in marks from pre-assessment (Basic Knowledge: $9.66 \pm 3.39$; Pre-Knowledge: $1.26 \pm 1.00$; Calculus I: $0.92 \pm 1.09$ ) to post-assessment (Basic Knowledge: $11.15 \pm 2.14$; Pre-Knowledge: $1.75 \pm 1.49$; Calculus I: 3.30 $\pm 1.86)$.

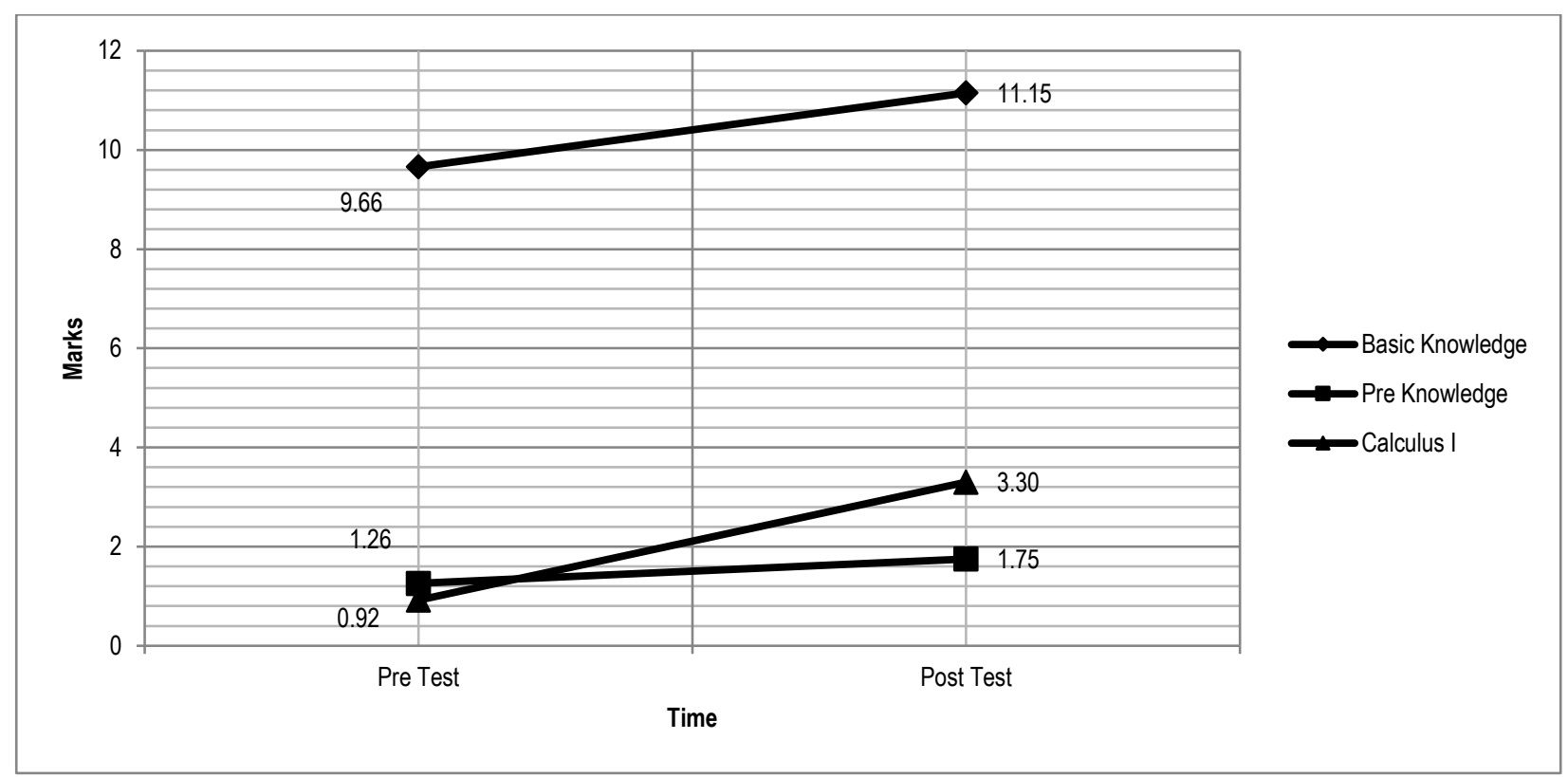

Figure 1: Graph Analysis of Pre-Assessment and Post-Assessment

Table 1 shows a series of three results of paired samples t-test of the targeted variables in this study for confirming the increment findings from the graph analysis in Figure 1. The analysis indicated that there is a significant increase of Basic Knowledge scores from pre-assessment to post-assessment (Mean Difference $=-1.49, \mathrm{t}(52)=-3.291, \mathrm{p}<.01)$ with the moderate effect sizes (Effect Sizes $=$ .172) (Cohen, 1988). The same situation also occurs for the Pre-Knowledge scores and Calculus I scores. The analysis indicates that there is a significant increase of Pre-Knowledge (Mean Difference $=-0.49, \mathrm{t}(52)=-2.167, \mathrm{p}<.05$ ) and Calculus I (Mean Difference $=$ $2.38, \mathrm{t}(52)=-9.559, \mathrm{p}<.01$ ) scores from pre-assessment to post-assessment. However, the effect sizes for the Pre-Knowledge (Effect Sizes $=.083$ ) analysis can be considered small effect sizes, whereas large effect sizes were found for the Calculus 1 (Effect Sizes = .637 ) analysis (Cohen, 1988).

Table 2: Summary Results of Paired Samples t-test

\begin{tabular}{|c|c|c|c|c|c|c|}
\hline Variable & Time & $\mathrm{M} \pm \mathrm{SD}$ & $\mathrm{MD} \pm \mathrm{SE}$ & t-statistics & $p$-value & Effect Size \\
\hline Basic Knowledge & $\begin{array}{c}\text { Pre-test } \\
\text { Post-test }\end{array}$ & $\begin{array}{c}9.66 \pm 3.39 \\
11.15 \pm 2.14\end{array}$ & $-1.49 \pm 0.45$ & -3.291 & $.002^{\star *}$ & .172 \\
\hline Pre Knowledge & $\begin{array}{c}\text { Pre-test } \\
\text { Post-test }\end{array}$ & $\begin{array}{l}1.26 \pm 1.00 \\
1.75 \pm 1.49\end{array}$ & $-0.49 \pm 0.23$ & -2.167 & $.035^{*}$ & .083 \\
\hline Calculus I & $\begin{array}{l}\text { Pre-test } \\
\text { Post-test }\end{array}$ & $\begin{array}{l}0.92 \pm 1.09 \\
3.30 \pm 1.86\end{array}$ & $-2.38 \pm 0.25$ & -9.559 & $<.001^{* *}$ & 637 \\
\hline
\end{tabular}

Note: Bonferroni Correction Alpha $=.017$ (Level of Significance / Number of Paired Samples t-test); $n=53 ; M=$ Mean; MD = Mean Difference; SD = Standard Deviation; $S E=$ Standard Error; ${ }^{*} p<.05 ;{ }^{* *} p<.01$.

Since the analysis can be considered facing a possibility of Type 1 error problems due to a series of the paired samples t-test from one source of experiments design (Field, 2009), Bonferroni Correction Alpha was performed. By using the new correction alpha, the 
analysis indicates that there is a significant increase of Basic Knowledge (Mean Difference $=-1.49, t(52)=-3.291, p<.016$ ) and Calculus $\mathrm{I}$ (Mean Difference $=-2.38, \mathrm{t}(52)=-9.559, \mathrm{p}<.016)$ scores from the pre-assessment to post-assessment, with the moderate (Basic Knowledge: .172) and large (Calculus I: .637) effect sizes. However, the analysis also indicates that Pre-Knowledge scores did not statistically significant increase (Mean Difference $=-0.49, t(52)=-2.167, p=.035$ ) from pre-assessment to post-assessment, since the $p$-value was greater than .016. It is also supported by the analysis of effect sizes for these Pre-Knowledge scores, where the effect size was small (Effect Sizes $=.083$ ).

\subsection{Discussion}

In this research, the collaborative teaching method was used to teach 53 Diploma-level Calculus I students. The method was applied between a pre-assessment test and a post-assessment test. The questions were separated into three categories: Basic Knowledge, Pre-Knowledge and Calculus I. The scores for these three categories from both assessments were then calculated and analyzed. From the results, the scores for Basic Knowledge and knowledge of Calculus I show a significant increase statistically. This indicates that using the collaborative teaching method to teach the concepts of Mathematics and Calculus is effective. By using this method, students have a better understanding of the concepts, and hence, can achieve better scores during their post-assessment test. However, the score for Pre-Knowledge was found to be increasing, but statistically insignificant. This implies that although this method may have helped to increase the score, the students already have their understanding of the information based on the prior knowledge obtained in their previous schools. This result supports previous research (Nopiah et al., 2015) which states that their pre-university results do not directly influence their grades in university.

Therefore, it can be concluded that the scores of Basic Knowledge and Calculus I from pre-assessment to post-assessment statistically significant increased. In contrast, the scores of Pre-Knowledge from pre-assessment to post-assessment were found to be not statistically significant increased. The distribution of data scores can be considered normally distributed since the number of sample sizes can be classified as large samples (i.e. sample sizes > 30) according to Central Limit Theorem (Field, 2009), hence producing valid and unbiased results.

\subsection{Conclusion and Recommendations}

Based on this research, it can be concluded that the collaborative teaching method is effective and useful in teaching Calculus I in UiTMCJ, because the analyses show positive results, as the scores for all three categories increase. Therefore, it is recommended to use the collaborative teaching method in teaching Calculus I. It is also suggested that future researches perform a test to determine the effectiveness of using a tool such as a custom-made module in teaching Calculus I. This recommendation is made to compare the results of teaching using a method with teaching using tools.

\section{Acknowledgments}

The Institute of Research Management and Innovation (IRMI) of UiTM supports this research by providing the Academic and Research Assimilation research grant, code 600-IRMI/DANA 5/3/ARAS (0085/2016).

\section{References}

Ahmad, S.N., Mahadi, S., Yusri, M.Y., Yusop, H., Ali, M.N., \& Chu, H.H. (2017). Factors Related to Students' Performance in Calculus. Journal of Applied Environmental and Biological Sciences, 7(6S), 51-56.

Burns, A. (2014). "Calculus Students' Understanding of the Derivative in Relation to the Vertex of a Quadratic Function." Dissertation, Georgia State University, 2014.

Cohen, J.W. (1988). Statistical Power Analysis for the Behavioral Sciences (2nd Edition). Hillsdale, NJ: Lawrance Erlbaum Associates.

Davidson, N., \& Major, C. H. (2014). Boundary crossings: Cooperative learning, collaborative learning, and problem-based learning. Journal on Excellence in College Teaching, 25(3\&4), 7-55.

Diaz, V., Brown, M., \& Salmons, J. (2010, June 1) . ELI Discovery Tool: Guide to Collaborative Learning. Retrieved from https://library.educause.edu/resources/2010/6/elidiscovery-tool-guide-to-collaborative-learning

Engelbrecht, J., Bergsten, C., \& Kagesten, O. (2012). Conceptual and Procedural Approaches to Mathematics in the Engineering Curriculum: Student Conceptions and Performance. Journal of Engineering Education Volume 101, Issue 1, 138-162

Engelbrecht, J., Harding, A., \& Potgieter, M. (2005). Undergraduate students' performance and confidence in procedural and conceptual mathematics. International Journal of Mathematical Education in Science and Technology Vol. 36 , Iss. 7, 701-712.

Field, A. (2009). Discovering Statistics Using SPSS (3rd Edition). London: SAGE Publications.

Hagman, J. E., Johnson, E., \& Fosdick, B. K. (2017). Factors contributing to students and instructors experiencing a lack of time in college calculus. International Journal of STEM Education (2017) 4:12. 
Hailikari, T., Katajavuori, N., \& Lindblom-Ylanne, S. (2008). The Relevance of Prior Knowledge in Learning and Instructional Design. American Journal of Pharmaceutical Education 2008; 72(5), Article 113

Hasanpour-Dehkordi, A., \& Solati, K. (2016). The Efficacy of Three Learning Methods Collaborative, Context-Based Learning and Traditional, on Learning, Attitude and Behaviour of Undergraduate Nursing Students: Integrating Theory and Practice. Journal of Clinical and Diagnostic Research, 2016 Apr, Vol-10(4), VC01-VC04.

Laal, M., \& Ghodsi, S. M. (2012). Benefits of collaborative learning. Procedia - Social and Behavioral Sciences 31 (2012), 486-490.

Laal, M., Khattami-Kermanshahi, Z., \& Laal, M. (2014). Teaching and education; collaborative style. Procedia - Social and Behavioral Sciences 116 (2014), $4057-4061$.

Mann, M., \& Enderson, M. (2017). Give Me a Formula Not the Concept! Student Preference to Mathematical Problem Solving. Journal for Advancement of Marketing Education, 25, 15-24

Nopiah, Z. M., Fuaad, N. F. A., Tawil, N. M., Hamzah, F. M., \& Othman, H. (2015). Student Achievement at Pre-University Level: Does it Influence the Achievement at the University? Journal of Engineering Science and Technology Special Issue, June (2015), 68-76.

Petocz, P., Reid, A., Wood, L. N., Smith, G. H., Mather, G., Harding, A., Engelbrecht, J., Houston, K., Hillel, J., \& Perrett, G. (2007). Undergraduate Students' Conceptions of Mathematics: An International Study. International Journal of Science and Mathematics Education (2007)5, 439-459.

Serhan, D. (2015). Students' understanding of the definite integral concept. International Journal of Research in Education and Science (IJRES), 1(1), 84-88. 